\title{
Anatomic reconstruction of the acromioclavicular joint provides the best functional outcomes in the treatment of chronic instability
}

\author{
Giuseppe Sircana ${ }^{1} \cdot$ Maristella F. Saccomanno $^{1}$ (1) $\cdot$ Fabrizio Mocini ${ }^{1} \cdot$ Vincenzo Campana ${ }^{1} \cdot$ Piermarco Messinese $^{1}$. \\ Andrea Monteleone ${ }^{1} \cdot$ Andrea Salvi $^{2} \cdot$ Alessandra Scaini $^{2} \cdot$ Almerico Megaro $^{3}$ - Giuseppe Milano ${ }^{2,3}$
}

Received: 21 March 2020 / Accepted: 10 May 2020

(c) European Society of Sports Traumatology, Knee Surgery, Arthroscopy (ESSKA) 2020

\begin{abstract}
Purpose To systematically review the outcomes of surgical treatments of chronic acromioclavicular joint dislocation. Methods Studies were identified by electronic databases (Ovid, PubMed). All studies reporting functional and radiological outcomes of surgical treatments of chronic acromioclavicular joint dislocations were included. Following data were extracted: authors and year, study design, level of evidence, number of patients, age, classification of acromioclavicular joint dislocation, time to surgery, surgical technique, follow-up, clinical and imaging outcomes, complications and failures. Descriptive statistics was used, when a data pooling was not possible. Comparable outcomes were pooled to generate summary outcomes reported as frequency-weighted values. Quality appraisal was assessed through the MINORS checklist.

Results Fourty-four studies were included for a total of 1020 shoulders. Mean age of participants was 38 years. Mean followup was 32.9 months. Arthroscopic techniques showed better results than open approach $(p<0.0001)$. Synthetic reconstructions demonstrated better functional outcomes compared to internal fixation and biologic techniques $(p<0.0001)$. Among biologic techniques, combined coracoclavicular and acromioclavicular ligaments reconstruction showed better Constant $(p=0.0270)$ and ASES $(p=0.0113)$ scores compared to isolated coracoclavicular ligaments reconstruction; anatomic biologic non-augmented graft reconstruction showed better Constant $(p<0.0001)$, VAS $(p<0.0001)$ and SSV $(p=0.0177)$ results compared to augmented techniques. No differences in functional outcomes could be found between anatomic biologic nonaugmented graft versus synthetic reconstructions. Overall, methodological quality of the included studies was low.
\end{abstract}

Conclusion Anatomic reconstructions, both synthetic and biologic, showed the best functional results.

Level of evidence IV.

Keywords Acromioclavicular joint $\cdot$ Chronic $\cdot$ Dislocations $\cdot$ Instability $\cdot$ Surgical treatment $\cdot$ Biologic $\cdot$ Synthetic $\cdot$ Graft . Plates

\section{Introduction}

Acromioclavicular (AC) joint dislocations account for 9-12\% of shoulder girdle injuries [7, 38], affecting especially young males [49] in their second-third decades [38]. They mainly occur through either a direct impact on the shoulder [60] or by an indirect force from a fall on the outstretched hand [38], typically during contact sports [49].

Electronic supplementary material The online version of this article (https://doi.org/10.1007/s00167-020-06059-5) contains supplementary material, which is available to authorized users.

Maristella F. Saccomanno

maristellasaccomanno@hotmail.it

Extended author information available on the last page of the article
In the chronic setting, main indication to surgical reconstruction is largely recognised as failure of conservative treatment of Rockwood type III-V dislocations with residual pain and functional impairment [45].

However, similar to the surgical treatment of acute AC joint dislocation, a wide variety of open or arthroscopic techniques have been proposed [41, 48], albeit no gold standard has been yet defined. What is more, it is still unclear whether surgical management in acute and chronic setting deserves a different approach and the available literature is quite lacking and confusing on this topic.

In the last decades, the general surgical trend has shifted from non-anatomic reconstructions to more anatomic and biological approaches. However, recent systematic reviews $[9,71]$, which compared surgical reconstruction techniques 
in the chronic setting, could not demonstrate any differences in clinical results as well as failure rates and complications, even if they both concluded by suggesting the use of anatomic techniques as a preferable option.

The purpose of the present study was to systematically review the outcomes of surgical techniques of AC joint reconstruction in the chronic setting and determine if a surgical technique is better than another. The hypothesis of the study was that anatomic biologic AC joint reconstruction would result in better postoperative outcomes.

\section{Materials and methods}

This systematic review was conducted according to the PRISMA (Preferred Reporting Items for Systematic reviews and Meta-Analyses) guidelines [42].

\section{Literature search}

Studies were identified by scanning major electronic databases (Ovid, PubMed). No limits were applied for language and publication date. Articles available only as e-publication and articles e-published ahead of a print were included as well. The search was applied to MEDLINE through Ovid, and then adapted for PubMed. All databases were examined from their inception up to March 03, 2020. Full search strategies are available on Online Appendix 1.

All studies reporting functional and radiological outcomes as well as revision rates after surgical treatment of chronic AC joint dislocations were included in the review. Studies with level of evidence (LOE) I-IV were included. Both open and arthroscopic approaches were considered eligible. Studies including either acute or revision cases were excluded, unless separate data for chronic cases were available. Similarly, studies comparing surgical versus conservative treatment were also included, with only the data from the surgical cases included in this analysis. Titles of journals, names of authors or supporting institutions were not masked at any stage. Animal studies, biomechanical studies, case reports, technical notes, reviews, expert opinions and editorial pieces were excluded.

Two independent reviewers screened studies for eligibility. A first screening was based on titles and abstracts resulted from the search. Disagreement between the two reviewers was assessed by a third researcher, who took the final decision. Selected studies were screened again based on the full text by the same independent reviewers. Again, any disagreement was judged by a third reviewer or solved by consensus.

\section{Data extraction}

A data extraction form was developed on an electronic spreadsheet (Excel, Microsoft Corporation, Redmond, WA, USA). The form was tested on five included studies, then reassessed and refined. The following fields were included in the form and, therefore, the following data were extracted from the full text of each included study: authors, year of publication, study design (prospective or retrospective), LOE, number of shoulders, patients' age, type of dislocation (according to Rockwood classification) time elapsed from injury to surgery, surgical approach, surgical technique, length of follow-up, functional and subjective outcomes, loss of reduction, revision and complications. When data were unclear or unavailable, no attempt was made to contact authors to obtain more information regarding methodology and findings.

Data were extracted by one author and checked by another independent reviewer. During data extraction, references of included articles were examined to search for missed studies. Although all functional outcomes were reported in the data extraction form, only the most commonly reported scores were used for data analysis.

\section{Data analysis}

Findings across all included studies were summarised with descriptive statistics, when a data pooling was not possible. Comparable outcome data from individual studies were pooled to generate summary outcomes reported as frequency-weighted values (weighted mean and standard deviation). Number of shoulders in individual studies were used to determine the weight of reported outcomes and used to calculate the weighted values. Between-group differences for continuous variables were analysed with Student's $t$ test. Statistical significance was set at $p<0.05$. Data were analysed with the GraphPad software (GraphPad Software, Inc., CA, USA).

\section{Quality appraisal}

Validity of the included studies was assessed through a checklist for non-randomised clinical trials, named methodological index for non-randomized studies (MINORS) [57]. It comprises 12 items, four of which are exclusive for comparative trials. The eight common domains are: aim statement, inclusion of consecutive patients, prospective collection of data, endpoint appropriateness, unbiased assessment, appropriateness of follow-up period, loss to follow-up and study size calculation. The four items for comparative studies are: adequateness of control group, contemporality of groups evaluation, baseline equivalence 
of groups and adequateness of statistical analysis. Each item is scored from 0 to 2: 0 for "not reported"; 1 for "reported but inadequate" and 2 for "reported and adequate". According to Moatshe et al. [41], studies were considered as at low risk of bias if 13 points were scored in non-comparative studies and if 21 points were scored in comparative studies. Two independent authors separately evaluated each included study with the MINORS checklist. The score of each item was compared; if disagreement existed, a third author reassessed the item and took the final decision.

Fig. 1 PRISMA flow diagram for the selection of studies

\section{Results}

\section{Study selection}

The search of electronic databases resulted in 232 studies. After screening and eligibility assessment (Fig. 1), 44 studies $[1,2,5,6,8,10,11,14-16,18,19,22,24,25,27-34,36$, $37,39,40,43,44,46,47,50,51,54,58,59,62-65,67-70]$ were finally included in the review.

\section{Study characteristics}

No LOE-I studies could be found. Seventeen studies [1, 6, $8,11,15,18,34,37,39,43,47,50,54,62,63,69]$ were

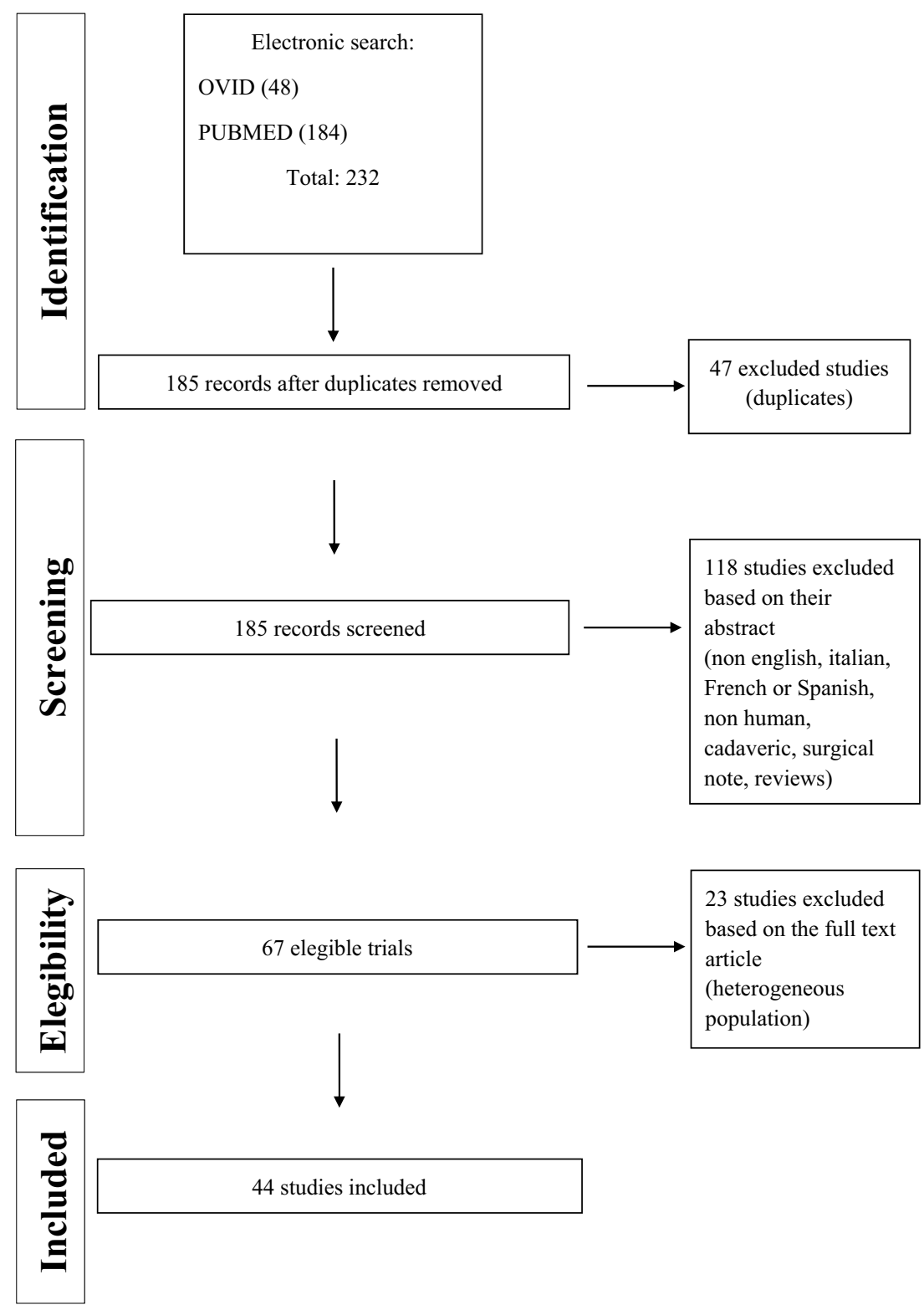


prospective in nature, while $27[2,5,10,14,16,19,22$, $24,25,27-33,36,40,46,51,58,59,64,65,67,68,70]$ were retrospective. The included studies involved 1020 shoulders. Mean age of participants was $38 \pm 5.6$ years (range 18-78 years). The mean length of follow-up of was $32.9 \pm 18.3$ months (range 4-155 months).

According to the Rockwood classification, 351 type III, 41 type IV, 229 type V and one type VI AC joint dislocations were included. Time from injury to surgery was more than 2 weeks in four studies [14-16, 70], more than 1 month in six studies $[19,22,39,58,59,68]$, more than 6 weeks in 10 studies $[5,11,27,29,30,37,46,50,51$, 54], more than 3 months in 11 studies [1, 2, 6, 8, 10, 28, $33,63-65]$, more than 6 months in 11 studies [10, 18, 24, $25,34,43,44,47,62,63,67]$, and not reported in one study [31].

For reporting purposes, surgical techniques were divided into open and arthroscopic, and grouped as biologic reconstruction techniques, when a biologic graft or transposition was used; synthetic reconstructions, when artificial ligaments or buttons were used; or internal fixation, when hardware, such as plate or screws, was used. Surgical techniques are summarised in Table 1.

Several scores were used to report functional outcomes among studies. The most common were: Constant score [13] in 27 studies $[2,5,6,10,11,18,25,27,28,31-33,36,37$, 40, 44, 46, 50, 51, 54, 59, 62-65, 67, 70], Visual Analogic Scale (VAS) for pain in 10 studies [10, 15, 22, 24, 25, 27, 46, 50, 64, 67], American Shoulder and Elbow Surgeons (ASES) society standardised shoulder assessment form [52] in seven studies [11, 22, 31, 39, 59, 62, 63], Subjective Shoulder Value (SSV) [21] in seven studies [8, 10, 15, 25, 32, 50, 63] and Disabilities of the Arm, Shoulder and Hand (DASH) score [26] in six studies [15, 29, 46, 54, 64, 65].

Loss of reduction was reported in 35 studies $[1,2,5,8$, $11,14-16,18,19,22,24,27-30,32-34,36,37,39,46,47$,
50, 51, 54, 58, 63-65, 67-70]. Definitions are summarised in Table 2.

Data extracted from each of the included studies are reported in Online Appendix 2.

\section{Open vs arthroscopic techniques}

Main characteristics of studies based on surgical approach are reported in Table 3. Two studies $[39,58]$ reported data on both open and arthroscopic techniques, whose results were not provided separately and were not included in the analysis.

Results of functional outcomes are reported in Table 4. Arthroscopic techniques demonstrated better functional results in terms of Constant score $(p=0.018)$, DASH $(p<0.0001)$, SSV $(p<0.0001)$ and lower residual pain at VAS score $(p<0.0001)$.

\section{Biologic reconstruction vs synthetic reconstruction vs internal fixation}

Main characteristics of different surgical techniques grouped as described above are summarized in Table 5. Clinical outcomes are reported in Table 6. Synthetic reconstruction showed statistically significant better results in all explored outcomes.

\section{Comparison between biologic reconstruction techniques}

In the biologic reconstruction group, a further comparison has been performed between ligament transfer techniques, tendon autograft reconstruction techniques and tendon allograft reconstruction techniques. Studies reporting results of these techniques with synthetic augmentation were not included in the comparison.

Table 1 Surgical techniques

\begin{tabular}{|c|c|c|}
\hline Biologic & Synthetic & Internal fixation \\
\hline Autograft $[22,24,54,62-64]$ & Artificial ligaments $[6,19,28,34,37,70]$ & Hook plate $[18]$ \\
\hline $\begin{array}{l}\text { Autograft with synthetic augmentation }[27,31,32,47 \text {, } \\
63]\end{array}$ & $\begin{array}{l}\text { Artificial ligaments augmented with } \\
\text { temporary k-wire }[19,65]\end{array}$ & Hook plate and Weaver Dunn $[10,25,40]$ \\
\hline Allograft $[29,39,44,58]$ & Double button [59] & Tension band and Weaver Dunn [1] \\
\hline Allograft with synthetic augmentation $[46,58]$ & & Bosworth screw and Weaver Dunn [51] \\
\hline Weaver-Dunn $[10,24,33,34,58,62,68]$ & & Hook plate and Cadenat [43] \\
\hline Weaver-Dunn augmented with buttons $[2,8,31]$ & & Hook plate and Dewar -Barrington [67] \\
\hline \multicolumn{3}{|l|}{ Weaver-Dunn augmented with artificial ligament [69] } \\
\hline \multicolumn{3}{|l|}{ Cadenat $[5,16]$} \\
\hline \multicolumn{3}{|l|}{ Cadenat augmented with buttons [15] } \\
\hline $\begin{array}{l}\text { Conjoined tendon and coracoacromial ligament transfer } \\
{[30,36]}\end{array}$ & & \\
\hline
\end{tabular}


Table 2 Main definitions of "reduction"

\begin{tabular}{|c|c|}
\hline Definition & Radiological examination \\
\hline $\begin{array}{l}\text { Side-to-side difference based on the width of the clavicle: } \\
\text { Maintained: no difference } \\
\text { Partial loss: }<100 \% \\
\text { Complete loss: }>100 \%\end{array}$ & Radiographs $[14,32,36,67,68]$ \\
\hline $\begin{array}{l}\text { Difference in the vertical distance between the inferior border of the acromion and the clavicle in comparison } \\
\text { with the contralateral side: } \\
\text { Anatomical: }<2 \mathrm{~mm} \\
\text { Slight loss: } 2-4 \mathrm{~mm} \\
\text { Partial loss: } 4-8 \mathrm{~mm} \\
\text { Total loss: }>8 \mathrm{~mm}\end{array}$ & $\begin{array}{l}\text { Radiographs }[28,51] \\
\text { Ultrasonography [27] }\end{array}$ \\
\hline $\begin{array}{l}\text { Ratio of translation and AC joint height length: } \\
\text { Slight loss: } 0.25-0.50 \\
\text { Re-dislocation: }>0.50\end{array}$ & Radiographs [37] \\
\hline $\begin{array}{l}\text { Residual AC joint displacement: } \\
\text { Subluxation: }<1 \mathrm{~cm} \\
\text { Dislocation: }>1 \mathrm{~cm}\end{array}$ & Radiographs [15] \\
\hline $\begin{array}{l}\text { Displacement of the clavicle in relation to the height of the acromion of the non-injured side: } \\
\text { Reduced: no displacement } \\
\text { Subluxated: }<50 \% \\
\text { Completely dislocated: }>50 \%\end{array}$ & Radiographs [46] \\
\hline $\begin{array}{l}\text { Horizontal failure } \\
\text { Anteroposterior translation compared with the uninjured side: } \\
\text { Stable: }<50 \% \\
\text { Subluxated: } 50 \%-100 \% \\
\text { Dislocated: }>100 \% \\
\text { Vertical failure } \\
25-100 \% \text { increase in the CC distance compared with the contralateral side }\end{array}$ & Radiographs [63] \\
\hline Loss of a complete anatomical reduction of the $\mathrm{AC}$ joint in both the coronal and the axial plane & Radiographs [54] \\
\hline Vertical displacement $>50 \%$ of the $\mathrm{AC}$ joint & Radiographs [70] \\
\hline Subluxation of $3 \mathrm{~mm}$ or more in AP stress radiographs & Radiographs [5] \\
\hline $\begin{array}{l}\text { Increase } \geq 10 \mathrm{~mm} \text { in } \mathrm{CC} \text { distance of the injured shoulder between the first postoperative and any subsequent } \\
\text { radiograph or a side-to-side difference } \geq 10 \mathrm{~mm}\end{array}$ & Radiographs [39] \\
\hline Increased CC interval of $>5 \mathrm{~mm}$ compared with immediate post-operative radiographs & Radiographs [58] \\
\hline
\end{tabular}

$C C$ coracoclavicular, $A C$ acromioclavicular

Table 3 Main characteristics of included studies based on the surgical approach: open $v s$ arthroscopy

\begin{tabular}{lll}
\hline & Open techniques & Arthroscopic techniques \\
\hline Number of studies & $34[1,2,5,6,10,11,15,16,18,19,22,24,25$, & $7[8,14,27,32,46,47,50]$ \\
& $28-31,34,36,37,40,43,44,51,54,59,62-65$, & \\
& $67-70]$ & 80 \\
Number of shoulders & 755 & $11 / 80(13.8 \%)$ \\
Loss of reduction & $72 / 573(12.6 \%)$ & $7 / 62(11.3 \%)$ \\
Revisions & $20 / 532(3.8 \%)$ &
\end{tabular}

Main characteristics are summarised in Table 7 and clinical outcomes are reported in Table 8. No differences could be demonstrated in clinical outcomes among different groups except for VAS pain, in favour of autograft reconstruction $(p<0.0001)$ and ASES score in favour of allograft $(p<0.0001)$.

\section{Anatomic biologic reconstruction techniques comparison}

Two subgroup analyses were performed among studies reporting outcomes of anatomic biologic reconstruction techniques. First, isolated CC ligament versus combined 
Table 4 Clinical outcomes of open vs arthroscopic approach

\begin{tabular}{|c|c|c|c|c|c|}
\hline \multirow[t]{2}{*}{ Functional scores } & \multicolumn{2}{|l|}{ Open techniques } & \multicolumn{2}{|c|}{ Arthroscopic techniques } & \multirow[t]{2}{*}{$p$ value } \\
\hline & Included studies & Weighted mean \pm SD & Included studies & Weighted mean \pm SD & \\
\hline Constant & $\begin{array}{c}23[2,5,6,10,11,18,25,28,31,33,36 \\
37,40,44,51,54,59,62-65,67,70]\end{array}$ & $87.76 \pm 6.31$ & $4[27,32,46,50]$ & $89.93 \pm 6$ & 0.0181 \\
\hline VAS & $7[10,15,22,24,25,64,67]$ & $8.83 \pm 3.48$ & $3[27,46,50]$ & $2.29 \pm 1.93$ & $<0.0001$ \\
\hline DASH & $5[15,29,54,64,65]$ & $9.51 \pm 4.22$ & $1[46]$ & $2.61 \pm 1.69$ & $<0.0001$ \\
\hline ASES & $6[11,22,31,59,62,63]$ & $91.26 \pm 4.89$ & 0 & & \\
\hline SSV & $4[10,15,25,63]$ & $80.89 \pm 2.82$ & $2[8,50]$ & $89.32 \pm 8.80$ & $<0.0001$ \\
\hline
\end{tabular}

Table 5 Main characteristics of included studies based on surgical technique

\begin{tabular}{llll}
\hline & Biologic & Synthetic & Internal Fixation \\
\hline Number of studies & $30[2,5,8,10,11,14-16,22,24,27,29-34$, & $8[6,19,28,34,37,59,65,70]$ & $8[1,10,18,25,40,43,51,67]$ \\
Number of patients & $36,39,44,46,47,50,54,58,62-64,68,69]$ & & 107 \\
Distal clavicle excision & $110 / 404(27.2 \%)$ & 219 & - \\
Loss of reduction & $95 / 593(16.0 \%)$ & $40 / 219(18.3 \%)$ & $5 / 62(8.1 \%)$ \\
Revisions & $39 / 577(6.8 \%)$ & $22 / 182(12.1 \%)$ & $3 / 68(4.4 \%)$ \\
Number of complications & $111 / 491(22.6 \%)$ & $4 / 133(3.0 \%)$ & $30 / 101(29.7 \%)$ \\
Complications & Tunnel widening (29) & $20 / 219$ (9.1\%) & CC calcifications (15) \\
& Infection (28) & Infection (5) & Infection (6) \\
& Clavicle osteolysis (14) & Foreign-body reaction (4) & Hardware displacement (3) \\
& CC calcifications (13) & Prominence of screws (4) & Shoulder impingement (1) \\
& Coracoid fracture (8) & Coracoid fracture (3) & Haematoma (1) \\
& Clavicle fracture (5) & Clavicle fracture (1) & \\
& Persistent pain (5) & & \\
& Shoulder stiffness (3) & & \\
& Hardware mobilisation (2) & & \\
& Distal clavicle hypertrophy (2) & &
\end{tabular}

$C C$ coracoclavicular

Table 6 Clinical outcomes of surgical techniques

\begin{tabular}{|c|c|c|c|c|c|c|c|}
\hline \multirow[t]{2}{*}{ Functional scores } & \multicolumn{2}{|l|}{ Biologic } & \multicolumn{2}{|l|}{ Synthetic } & \multicolumn{2}{|l|}{ Internal fixation } & \multirow[t]{2}{*}{$p$ value } \\
\hline & Included studies & $\begin{array}{l}\text { Weighted mean } \\
\pm \mathrm{SD}\end{array}$ & Included studies & $\begin{array}{l}\text { Weighted mean } \\
\pm \mathrm{SD}\end{array}$ & Included studies & $\begin{array}{l}\text { Weighted mean } \\
\pm \mathrm{SD}\end{array}$ & \\
\hline Constant & $\begin{array}{l}16[2,5,10,11, \\
27,31-33,36, \\
44,46,50,54, \\
62-64]\end{array}$ & $87.93 \pm 5.78$ & $\begin{array}{l}6[6,28,37,59, \\
\quad 65,70]\end{array}$ & $90.60 \pm 6.44$ & $\begin{array}{l}6[10,18,25,40 \\
51,67]\end{array}$ & $86.36 \pm 7.81$ & $<0.0001$ \\
\hline VAS & $\begin{array}{c}8[10,15,22,24 \\
27,46,50,64]\end{array}$ & $11.22 \pm 11.52$ & 0 & & $3[10,25,67]$ & $17 \pm 15.13$ & 0.0036 \\
\hline DASH & $\begin{array}{l}5[15,29,46,54, \\
\quad 64]\end{array}$ & $9.57 \pm 5.05$ & $1[65]$ & $6.42 \pm 6$ & 0 & & 0.01 \\
\hline ASES & $\begin{array}{l}6[11,22,31,39 \\
62,63]\end{array}$ & $90.74 \pm 4.53$ & $1[59]$ & $97.5 \pm 3.70$ & 0 & & $<0.0001$ \\
\hline SSV & $\begin{array}{l}6[8,10,15,32, \\
50,63]\end{array}$ & $84.44 \pm 6.02$ & 0 & & $2[10,25]$ & $74.05 \pm 6,94$ & $<0.0001$ \\
\hline
\end{tabular}


Table 7 Main characteristics of studies including biologic techniques

\begin{tabular}{llll}
\hline & Transfer & Autograft & Allograft \\
\hline Number of studies & $11[5,10,16,24,30,33,34$, & $6[22,24,54,62-64]$ & $4[29,39,44,58]$ \\
& $36,58,62,68]$ & & \\
Number of patients & 191 & 109 & 143 \\
Loss of reduction & $29 / 187(15.5 \%)$ & $20 / 97(20.6 \%)$ & $27 / 122(22.1 \%)$ \\
Revisions & $12 / 198(6.1 \%)$ & $7 / 109(6.4 \%)$ & $11 / 122(9.0 \%)$ \\
\hline
\end{tabular}

Table 8 Clinical outcomes of biologic reconstruction techniques

\begin{tabular}{|c|c|c|c|c|c|c|c|}
\hline \multirow[t]{2}{*}{ Functional Scores } & \multicolumn{2}{|l|}{ Transfer } & \multicolumn{2}{|l|}{ Autograft } & \multicolumn{2}{|l|}{ Allograft } & \multirow[t]{2}{*}{$p$ value } \\
\hline & Included studies & $\begin{array}{l}\text { Weighted mean } \\
\pm \mathrm{SD}\end{array}$ & Included studies & $\begin{array}{l}\text { Weighted mean } \\
\pm \mathrm{SD}\end{array}$ & Included studies & $\begin{array}{l}\text { Weighted } \\
\text { mean } \pm \\
\text { SD }\end{array}$ & \\
\hline Constant & $5[5,10,33,36,62]$ & $87.96 \pm 3.88$ & $4[54,62-64]$ & $87.79 \pm 4.52$ & $1[44]$ & $86.6 \pm 18$ & ns \\
\hline VAS & $2[10,24]$ & $10 \pm 0$ & $3[22,24,64]$ & $8.15 \pm 2.4$ & 0 & & $<0.0001$ \\
\hline DASH & 0 & & $2[54,64]$ & $10.9 \pm 5.16$ & 1 [29] & $13 \pm 15$ & ns \\
\hline ASES & $1[62]$ & $86 \pm 8$ & $3[22,62,63]$ & $89.56 \pm 6.46$ & 1 [39] & $96.1 \pm 4$ & $<0.0001$ \\
\hline SSV & 0 & & $1[63]$ & $84.1 \pm 10.7$ & 0 & & \\
\hline
\end{tabular}

Table 9 Main characteristics of anatomical biologic reconstruction techniques with and without $\mathrm{AC}$ ligaments reconstruction

\begin{tabular}{lll}
\hline & Combined CC and AC & Isolated CC \\
\hline Number of studies & $7[11,29,32,44,54$, & $12[14,22,24,27,31$, \\
& $63,64]$ & $39,46,47,50,58$, \\
& & $62,63]$ \\
Number of patients & 126 & 293 \\
Loss of reduction & $20 / 105(19.0 \%)$ & $45 / 279(16.1 \%)$ \\
Revisions & $5 / 84(6.0 \%)$ & $23 / 273(8.4 \%)$ \\
\hline
\end{tabular}

$A C$ acromioclavicular, $C C$ coracoclavicular

$\mathrm{CC}$ and $\mathrm{AC}$ ligament reconstruction were compared; then, anatomic biologic graft reconstruction with or without synthetic augmentation was analysed.

Main characteristics of anatomical biologic reconstruction techniques comparing isolated and combined CC and AC ligaments reconstruction are reported in Table 9. Clinical results are reported in Table 10. Combined reconstruction of both $\mathrm{CC}$ and AC ligaments showed significant better functional results when evaluated through shoulder-specific questionnaires, such as Constant score $(p=0.0270)$ and ASES $(p=0.0113)$. On the opposite, DASH score $(p<0.0001)$ was significantly better when isolated CC ligament reconstruction was performed.

Comparison of anatomical biologic reconstruction techniques with and without synthetic augmentation are reported in Table 11. Clinical outcomes are reported in Table 12. Non-augmented techniques showed significant better Constant $(p<0.0001)$ and SSV $(p=0.0177)$ results, associated with lower residual pain at VAS $(p<0.0001)$. DASH score favoured augmented techniques $(p<0.0001)$.

A further comparison was made between anatomic biologic graft reconstruction techniques and synthetic

Table 10 Functional outcomes of combined CC and AC vs isolated CC ligaments reconstruction

\begin{tabular}{|c|c|c|c|c|c|}
\hline \multirow[t]{2}{*}{ Functional scores } & \multicolumn{2}{|l|}{ Combined $\mathrm{CC}$ and $\mathrm{AC}$} & \multicolumn{2}{|l|}{ Isolated CC } & \multirow[t]{2}{*}{$p$ value } \\
\hline & Included studies & Weighted mean \pm SD & Included studies & Weighted mean \pm SD & \\
\hline Constant & $6[11,32,44,54,63,64]$ & $88.27 \pm 4.29$ & $6[27,31,46,50,62,63]$ & $86.01 \pm 9.43$ & 0.0270 \\
\hline VAS & $1[64]$ & $10 \pm 20$ & $5[22,24,27,46,50]$ & $12.95 \pm 15.87$ & ns \\
\hline DASH & $3[29,54,64]$ & $11.44 \pm 4.01$ & $1[46]$ & $2.61 \pm 1.79$ & $<0.0001$ \\
\hline ASES & $2[11,63]$ & $93.2 \pm 2.24$ & $5[22,31,39,62,63]$ & $90.66 \pm 5.50$ & 0.0113 \\
\hline SSV & $1[63]$ & $84.1 \pm 10.7$ & $3[32,50,63]$ & $87.3 \pm 8.71$ & ns \\
\hline
\end{tabular}

CC coracoclavicular, $A C$ acromioclavicular 
Table 11 Main characteristics of anatomical biologic reconstruction techniques with and without synthetic augmentation

\begin{tabular}{lll}
\hline & Anatomic non augmented & Anatomic augmented \\
\hline Number of studies & $12[11,22,24,29,39,44,50,54,58$, & $8[14,27,31,32,46,47,58,63]$ \\
& $62-64]$ & \\
Number of patients & 285 & 134 \\
Loss of reduction & $47 / 219(21.5 \%)$ & $8 / 108(7.4 \%)$ \\
Revisions & $18 / 231(7.8 \%)$ & $5 / 90(5.6 \%)$ \\
\hline
\end{tabular}

Table 12 Anatomic biologic reconstruction: Non-augmented vs Augmented

\begin{tabular}{|c|c|c|c|c|c|}
\hline \multirow[t]{2}{*}{ Functional scores } & \multicolumn{2}{|l|}{ Anatomic non-augmented } & \multicolumn{2}{|l|}{ Anatomic augmented } & \multirow[t]{2}{*}{$p$ value } \\
\hline & Included studies & Weighted mean \pm SD & Included studies & Weighted mean \pm SD & \\
\hline Constant & $7[11,44,50,54,62-64]$ & $89.6 \pm 4.88$ & $5[27,31,32,46,63]$ & $83.40 \pm 8.12$ & $<0.0001$ \\
\hline VAS & $4[22,24,50,64]$ & $7.79 \pm 2.3$ & $2[27,46]$ & $25.78 \pm 27.22$ & $<0.0001$ \\
\hline DASH & $3[29,54,64]$ & $11.44 \pm 4.01$ & $1[46]$ & $2.61 \pm 1.79$ & $<0.0001$ \\
\hline ASES & $5[11,22,39,62,63]$ & $91.29 \pm 5.32$ & $2[31,63]$ & $91.47 \pm 4.58$ & ns \\
\hline SSV & $2[50,63]$ & $89.55 \pm 7.70$ & $2[32,63]$ & $84 \pm 8.48$ & 0.0177 \\
\hline
\end{tabular}

techniques. Only Constant scores could be compared and no differences between groups could be detected.

\section{Quality appraisal}

The methodological quality of the included studies was low. Only one non-comparative study was considered at low risk of bias [22]; while the other 31 studies [1, 2, 5, 6, 8, 11, 14-16, 18, 25, 27-30, 33, 36, 39, 40, 43, 44, 47, 50, 51, 54, $59,64,67-70]$ were considered at high risk of bias. Two comparative studies $[37,62]$ resulted at low risk of bias, while 12 studies [10, 19, 24, 31, 32, 34, 46, 58, 63, 65] resulted at high risk of bias.

Scoring for each MINORS domain of all the included studies is reported in Online Appendix 3.

\section{Discussion}

Main findings of this systematic review on chronic AC joint reconstruction techniques showed that arthroscopy was associated with significantly lower residual pain and better functional results, with no differences in postoperative rate of loss of reduction, but with higher revision rate, compared to the open approach. Among biologic, synthetic and internal fixation techniques, synthetic reconstruction provided better functional outcomes; whereas, internal fixation provided lower loss of reduction rate. However, it must be highlighted that 30 studies $[2,5,8,10,11,14-16,22,24,27,29-34$, $36,39,44,46,47,50,54,58,62-64,68,69]$ out of 44 [1, $2,5,6,8,10,11,14-16,18,19,22,24,25,27-34,36,37$, $39,40,43,44,46,47,50,51,54,58,59,62-65,67-70]$ focused on biologic reconstruction techniques. Therefore, further subgroup analysis was deemed necessary. Results showed that combined $\mathrm{CC}$ and AC ligaments reconstruction provided better shoulder-specific functional scores compared to isolated CC ligaments reconstruction. Moreover, anatomic biologic non-augmented graft reconstruction techniques showed better shoulder-specific functional scores when compared to augmented techniques and no significant differences when compared to synthetic reconstructions. Although available data allowed us to explore only differences in the Constant score, a comparison between anatomic biologic and synthetic reconstructions was attempted, as artificial ligaments were mostly used aiming to reconstruct CC ligaments: three studies [19, 37, 65] passed the artificial ligament through two bone tunnels in the lateral third of the clavicle and under the coracoid; four studies [6, 28, 34, 70] used the Surgilig, an artificial ligament with two loops and a fixation screw, which passes around the coracoid and over the clavicle; one study [59] used a continuous-loop double endobutton supplemented with a "trapezoid stitch". Comparable functional results between synthetic and biologic reconstructions probably mean that anatomy makes the difference rather than the type of graft. Therefore, hypothesis of the study could not be rejected.

Two recent systematic reviews $[9,71]$ explored the outcomes after surgical stabilisation of AC joint in a chronic setting. Xarà-Leite et al. [71] reviewed results of 28 studies. Surgical techniques were divided into two main groups: anatomic (biologic and synthetic reconstructions) and nonanatomic (Weaver-Dunn, Hook plates, tendon transfers). Both groups showed a significant improvement with similar pooled failure and re-operation rate. However, comparative studies showed better functional outcomes and less pain when an anatomic reconstruction was performed, thus 
suggesting anatomic reconstruction as a preferable option. Results from the present review strongly confirmed a significant superiority of anatomic reconstructions. Borbas et al. [9] included 27 studies. The authors arbitrarily set as a cutoff point for chronic setting, 6 weeks after trauma. They categorised surgical techniques as follows: non-biologic fixation (suture loops and synthetic ligaments), biologic fixation (autograft or allograft) and ligament and/or tendon transfer. They did not find any difference in complications and/or failure rates between groups. However, they highlighted that among the LOE-II studies, AC joint reconstruction with a tendon graft showed better functional outcomes. Results could not be entirely confirmed by the present review, since both synthetic and anatomic biologic reconstruction provided comparable functional scores. Differences could be mainly due to the different number of included studies.

Nevertheless, Borbas et al. [9] let us introduce another ongoing subject of controversy: the definition of "chronic" AC joint dislocation. Differences between acute and chronic setting could be reasonably related to the biological environment of the lesion and therefore, they must be taken into account in the surgical decision-making algorithm. The present review did not set any cut-off, since a clear definition has not been yet provided by the literature. Therefore, AC joint dislocations were considered chronic by some included studies if the trauma occurred more than 2 weeks before surgery $[14-16,70]$, as well as more than 6 months $[10,18$, $24,25,34,43,44,47,62,63,67]$. These differences may be explained by the fact that most of the time chronic surgery becomes the main treatment option only after failure of conservative treatment, which can variably last from 3 weeks up to 3 months.

Focusing on anatomy, the AC joint is primarily stabilised by CC (conoid and trapezoid) and AC ligaments (anterior, posterior, superior, and inferior), which act as primary restraint to superior-inferior and anterior-posterior translation, respectively. Biomechanical studies demonstrated that combined $\mathrm{CC}$ and $\mathrm{AC}$ ligaments reconstruction provides better results than isolated CC reconstruction [17, 55]. Despite various techniques for reconstruction have been described $[3,4,11,20,23,29,35,53,66]$, no clinical study has yet focused on the advantages of one technique over another. Data available from included studies allowed the present review to be the first to confirm the importance of a combined reconstruction of both $\mathrm{CC}$ and $\mathrm{AC}$ ligaments from a clinical standpoint.

If a distal clavicle excision (DCE) should be considered a mandatory step when treating chronic AC joint injuries is still controversial. Literature is lacking and no comparative studies ever explored this topic. A data pooling was not possible because most of the studies included some patients who underwent a DCE and clinical results were not separable.

Two important issues came up when focusing on clinical results: AC joint dedicated functional scores are still not widespread; and a clear definition of loss of reduction has not been provided yet.

Based on the results of the present paper, two studies $[27,32]$ used the TAFT score [61], two [32, 63] used the ACJI score [56] and two [24, 34] used the Nottingham clavicle score [12]. A data pooling was not possible due to the paucity of studies; therefore, the Constant score was finally chosen as a main comparison for functional evaluation, since it has been used in the majorities of included studies [2, 5, $6,10,11,18,25,27,28,31-33,36,37,40,44,46,50,51$, $54,59,62-65,67,70]$.

On the other hand, loss of reduction was the most commonly reported definition of failure after $\mathrm{AC}$ joint dislocation treatment. Unfortunately, despite agreeing on the importance of this parameter, authors did not agree on its definition. As shown in the results, multiple definitions have been provided. This wide variability increased the heterogeneity of its assessment among studies.

The present systematic review has some limitations. Mainly, the overall low quality of included studies compromised external validity of the review and decreased the strength of the produced evidence. The absence of LOE-I studies precluded the performance of a meta-analysis. For this reason, frequency-weighted means were used for the comparisons, when possible. Moreover, included studies showed heterogeneity regarding either definition of chronic setting as well as characteristics of included patients, such as different Rockwood types included without stratification of results. Furthermore, the conspicuous number of available and reported surgical techniques among the different studies resulted in the need for categorising the techniques in broader groups, improving generalizability, but decreasing precision of the results. Finally, the absence of a univocal definition of loss of reduction as well as the amount of different clinical outcomes impaired the comparisons of groups.

\section{Conclusions}

Good functional outcomes can be expected from surgical treatment of chronic AC joint dislocation. Anatomic reconstructions, regardless of if a tendon or a synthetic graft is used, showed the best functional results. Overall quality of evidence is hindered by the low quality of the available studies. 


\section{Compliance with ethical standards}

Funding No external funding was used.

Conflict of interest The authors declare that they have no competing interest.

Ethical approval This article does not contain any studies with human participants performed by any of the authors.

Informed consent For this type of study formal consent is not required.

\section{References}

1. Adam FF, Farouk O (2004) Surgical treatment of chronic complete acromioclavicular dislocation. Int Orthop 28:119-122

2. Al-Ahaideb A (2014) Surgical treatment of chronic acromioclavicular joint dislocation using the Weaver-Dunn procedure augmented by the TightRope ${ }^{\circledR}$ system. Eur J Orthop Surg Traumatol 24:741-745

3. Banffy MB, van Eck CF, ElAttrache NS (2018) Clinical outcomes of a single-tunnel technique for coracoclavicular and acromioclavicular ligament reconstruction. J Shoulder Elbow Surg 27:S70-S75

4. Beitzel K, Obopilwe E, Apostolakos J, Cote MP, Russell RP, Charette R, Singh H, Arciero RA, Imhoff AB, Mazzocca AD (2014) Rotational and translational stability of different methods for direct acromioclavicular ligament repair in anatomic acromioclavicular joint reconstruction. Am J Sports Med 42:2141-2148

5. Bezer M, Saygi B, Aydin N, Kucukdurmaz F, Ekinci G, Guven O (2009) Quantification of acromioclavicular reduction parameters after the Weaver-Dunn procedure. Arch Orthop Trauma Surg 129:1017-1024

6. Bhattacharya R, Goodchild L, Rangan A (2008) Acromioclavicular joint reconstruction using the Nottingham Surgilig: a preliminary report. Acta Orthop Belg 74:167-172

7. Bishop JY, Kaeding C (2006) Treatment of the acute traumatic acromioclavicular separation. Sports Med Arthrosc Rev 14:237-245

8. Boileau P, Old J, Gastaud O, Brassart N, Roussanne Y (2010) All-arthroscopic Weaver-Dunn-Chuinard procedure with doublebutton fixation for chronic acromioclavicular joint dislocation. Arthroscopy 26:149-160

9. Borbas P, Churchill J, Ek ET (2019) Surgical management of chronic high-grade acromioclavicular joint dislocations: a systematic review. J Shoulder Elbow Surg 28:2031-2038

10. Boström Windhamre HA, von Heideken JP, Une-Larsson VE, Ekelund AL (2010) Surgical treatment of chronic acromioclavicular dislocations: a comparative study of Weaver-Dunn augmented with PDS-braid or hook plate. J Shoulder Elbow Surg 19:1040-1048

11. Carofino BC, Mazzocca AD (2010) The anatomic coracoclavicular ligament reconstruction: surgical technique and indications. $\mathrm{J}$ Shoulder Elbow Surg 19:37-46

12. Charles ER, Kumar V, Blacknall J, Edwards K, Geoghegan JM, Manning PA, Wallace WA (2017) A validation of the Nottingham Clavicle Score: a clavicle, acromioclavicular joint and sternoclavicular joint-specific patient-reported outcome measure. J Shoulder Elbow Surg 26:1732-1739
13. Constant CR, Murley AH (1987) A clinical method of functional assessment of the shoulder. Clin Orthope Relat Res 214:160-164

14. Cook JB, Shaha JS, Rowles DJ, Bottoni CR, Shaha SH, Tokish JM (2012) Early failures with single clavicular transosseous coracoclavicular ligament reconstruction. J Shoulder Elbow Surg 21:1746-1752

15. Defoort S, Verborgt $\mathrm{O}$ (2010) Functional and radiological outcome after arthroscopic and open acromioclavicular stabilization using a double-button fixation system. Acta Orthop Belg 76:585-591

16. Dumontier C, Sautet A, Man M, Apoil A (1995) Acromioclavicular dislocations: treatment by coracoacromial ligamentoplasty. J Shoulder Elbow Surg 4:130-134

17. Dyrna F, Imhoff FB, Haller B, Braun S, Obopilwe E, Apostolakos JM, Morikawa D, Imhoff AB, Mazzocca AD, Beitzel K (2018) Primary stability of an acromioclavicular joint repair is affected by the type of additional reconstruction of the acromioclavicular capsule. Am J Sports Med 46:3471-3479

18. Ejam S, Lind T, Falkenberg B (2008) Surgical treatment of acute and chronic acromioclavicular dislocation Tossy type III and V using the Hook plate. Acta Orthop Belg 74:441-445

19. Fraschini G, Ciampi P, Scotti C, Ballis R, Peretti GM (2010) Surgical treatment of chronic acromioclavicular dislocation: comparison between two surgical procedures for anatomic reconstruction. Injury 41:1103-1106

20. Freedman JA, Adamson GJ, Bui C, Lee TQ (2010) Biomechanical evaluation of the acromioclavicular capsular ligaments and reconstruction with an intramedullary free tissue graft. Am J Sports Med 38:958-964

21. Fuchs B, Jost B, Gerber C (2000) Posterior-inferior capsular shift for the treatment of recurrent, voluntary posterior subluxation of the shoulder. J Bone Joint Surg Am 82:16-25

22. Garofalo R, Ceccarelli E, Castagna A, Calvisi V, Flanagin B, Conti M, Krishnan SG (2017) Open capsular and ligament reconstruction with semitendinosus hamstring autograft successfully controls superior and posterior translation for type $V$ acromioclavicular joint dislocation. Knee Surg Sports Traumatol Arthrosc 25:1989-1994

23. Hann C, Kraus N, Minkus M, Maziak N, Scheibel M (2018) Combined arthroscopically assisted coraco- and acromioclavicular stabilization of acute high-grade acromioclavicular joint separations. Knee Surg Sports Traumatol Arthrosc 26:212-220

24. Hegazy G, Safwat H, Seddik M, Al-Shal EA, Al-Sebai I, Negm M (2016) Modified Weaver-Dunn procedure versus the use of semitendinosus autogenous tendon graft for acromioclavicular joint reconstruction. Open Orthop J 10:166-178

25. von Heideken J, Boström Windhamre H, Une-Larsson V, Ekelund A (2013) Acute surgical treatment of acromioclavicular dislocation type $\mathrm{V}$ with a hook plate: superiority to late reconstruction. J Shoulder Elbow Surg 22:9-17

26. Hudak PL, Amadio PC, Bombardier C (1996) Development of an upper extremity outcome measure: the DASH (disabilities of the arm, shoulder and hand) [corrected]. The Upper Extremity Collaborative Group (UECG). Am J Ind Med 29:602-608

27. Jensen G, Katthagen JC, Alvarado L, Lill H, Voigt C (2013) Arthroscopically assisted stabilization of chronic AC-joint instabilities in GraftRope ${ }^{\mathrm{TM}}$ technique with an additive horizontal tendon augmentation. Arch Orthop Trauma Surg 133:841-851

28. Jeon I-H, Dewnany G, Hartley R, Neumann L, Wallace WA (2007) Chronic acromioclavicular separation: the medium term results of coracoclavicular ligament reconstruction using braided polyester prosthetic ligament. Injury 38:1247-1253

29. Kibler WB, Sciascia AD, Morris BJ, Dome DC (2017) Treatment of symptomatic acromioclavicular joint instability by a docking technique: clinical indications, surgical technique, and outcomes. Arthroscopy 33:696-708.e2 
30. Kim SH, Lee YH, Shin SH, Lee YH, Baek GH (2012) Outcome of conjoined tendon and coracoacromial ligament transfer for the treatment of chronic type $\mathrm{V}$ acromioclavicular joint separation. Injury 43:213-218

31. Kocaoglu B, Ulku TK, Gereli A, Karahan M, Türkmen M (2017) Palmaris longus tendon graft versus modified Weaver-Dunn procedure via dynamic button system for acromioclavicular joint reconstruction in chronic cases. J Shoulder Elbow Surg 26:1546-1552

32. Kraus N, Hann C, Minkus M, Maziak N, Scheibel M (2019) Primary versus revision arthroscopically-assisted acromio- and coracoclavicular stabilization of chronic AC-joint instability. Arch Orthop Trauma Surg 139:1101-1109

33. Kumar S, Penematsa SR, Selvan T (2007) Surgical reconstruction for chronic painful acromioclavicular joint dislocations. Arch Orthop Trauma Surg 127:481-484

34. Kumar V, Garg S, Elzein I, Lawrence T, Manning P, Wallace WA (2014) Modified Weaver-Dunn procedure versus the use of a synthetic ligament for acromioclavicular joint reconstruction. $\mathrm{J}$ Orthop Surg Hong Kong 22:199-203

35. Lädermann A, Grosclaude M, Lübbeke A, Christofilopoulos P, Stern R, Rod T, Hoffmeyer P (2011) Acromioclavicular and coracoclavicular cerclage reconstruction for acute acromioclavicular joint dislocations. J Shoulder Elbow Surg 20:401-408

36. Lee SK, Song DG, Choy WS (2015) Anatomical double-bundle coracoclavicular reconstruction in chronic acromioclavicular dislocation. Orthopedics 38:e655-662

37. Marcheggiani Muccioli GM, Manning C, Wright P, Grassi A, Zaffagnini S, Funk L (2016) Acromioclavicular joint reconstruction with the LARS ligament in professional versus nonprofessional athletes. Knee Surg Sports Traumatol Arthrosc 24:1961-1967

38. Mazzocca AD, Arciero RA, Bicos J (2007) Evaluation and treatment of acromioclavicular joint injuries. Am J Sports Med 35:316-329

39. Millett PJ, Horan MP, Warth RJ (2015) Two-year outcomes after primary anatomic coracoclavicular ligament reconstruction. Arthroscopy 31:1962-1973

40. Mitev K, Zafiroski G, Mladenovski S, Nikolov L (2019) Surgical outcomes after fixation of acromioclavicular joint dislocation with hook plate and coracoacromial ligament transfer technique. Open Access Maced J Med Sci 7:1013-1015

41. Moatshe G, Kruckeberg BM, Chahla J, Godin JA, Cinque ME, Provencher MT, LaPrade RF (2018) Acromioclavicular and coracoclavicular ligament reconstruction for acromioclavicular joint instability: a systematic review of clinical and radiographic outcomes. Arthroscopy 34:1979-1995.e8

42. Moher D, Liberati A, Tetzlaff J, Altman DG, PRISMA Group (2009) Preferred reporting items for systematic reviews and metaanalyses: the PRISMA statement. PLoS Med 6:e1000097

43. Moriyama H, Gotoh M, Mitsui Y, Yoshikawa E, Uryu T, Okawa T, Higuchi F, Shirahama M, Shiba N (2014) Clinical outcomes of the Cadenat procedure in the treatment of acromioclavicular joint dislocations. Kurume Med J 61:17-21

44. Muench LN, Kia C, Jerliu A, Murphy M, Berthold DP, Cote MP, Arciero RA, Mazzocca AD (2019) Functional and radiographic outcomes after anatomic coracoclavicular ligament reconstruction for type III/V acromioclavicular joint injuries. Orthop J Sports Med 7:2325967119884539

45. Natera Cisneros L, Sarasquete Reiriz J (2017) Management of chronic unstable acromioclavicular joint injuries. J Orthop Traumatol 18:305-318

46. Natera Cisneros L, Sarasquete Reiriz J (2017) Unstable acromioclavicular joint injuries: is there really a difference between surgical management in the acute or chronic setting? J Orthop $14: 10-18$
47. Nordin JS, Aagaard KE, Lunsjö K (2015) Chronic acromioclavicular joint dislocations treated by the GraftRope device. Acta Orthop 86:225-228

48. North AS, Wilkinson T (2018) Surgical reconstruction of the acromioclavicular joint: can we identify the optimal approach? Strategies Trauma Limb Reconstr 13:69-74

49. Pallis M, Cameron KL, Svoboda SJ, Owens BD (2012) Epidemiology of acromioclavicular joint injury in young athletes. Am J Sports Med 40:2072-2077

50. Parnes N, Friedman D, Phillips C, Carey P (2015) Outcome after arthroscopic reconstruction of the coracoclavicular ligaments using a double-bundle coracoid cerclage technique. Arthroscopy 31:1933-1940

51. Pavlik A, Csépai D, Hidas P (2001) Surgical treatment of chronic acromioclavicular joint dislocation by modified Weaver-Dunn procedure. Knee Surg Sports Traumatol Arthrosc 9:307-312

52. Richards RR, An KN, Bigliani LU, Friedman RJ, Gartsman GM, Gristina AG, Iannotti JP, Mow VC, Sidles JA, Zuckerman JD (1994) A standardized method for the assessment of shoulder function. J Shoulder Elbow Surg 3:347-352

53. Saccomanno MF, Ieso DEC, Milano G (2014) Acromioclavicular joint instability: anatomy, biomechanics and evaluation. Joints 2:87-92

54. Saccomanno MF, Fodale M, Capasso L, Cazzato G, Milano G (2014) Reconstruction of the coracoclavicular and acromioclavicular ligaments with semitendinosus tendon graft: a pilot study. Joints 2:6-14

55. Saier T, Venjakob AJ, Minzlaff $P$, Föhr P, Lindell F, Imhoff AB, Vogt S, Braun S (2015) Value of additional acromioclavicular cerclage for horizontal stability in complete acromioclavicular separation: a biomechanical study. Knee Surg Sports Traumatol Arthrosc 23:1498-1505

56. Scheibel M, Dröschel S, Gerhardt C, Kraus N (2011) Arthroscopically assisted stabilization of acute high-grade acromioclavicular joint separations. Am J Sports Med 39:1507-1516

57. Slim K, Nini E, Forestier D, Kwiatkowski F, Panis Y, Chipponi J (2003) Methodological index for non-randomized studies (minors): development and validation of a new instrument. ANZ J Surg 73:712-716

58. Spencer HT, Hsu L, Sodl J, Arianjam A, Yian EH (2016) Radiographic failure and rates of re-operation after acromioclavicular joint reconstruction: a comparison of surgical techniques. Bone Jt J 98-B:512-518

59. Struhl S, Wolfson TS (2015) Continuous Loop Double Endobutton Reconstruction for Acromioclavicular Joint Dislocation. Am J Sports Med 43:2437-2444

60. Stucken C, Cohen SB (2015) Management of acromioclavicular joint injuries. Orthop Clin N Am 46:57-66

61. Taft TN, Wilson FC, Oglesby JW (1987) Dislocation of the acromioclavicular joint. An end-result study. J Bone Joint Surg Am 69:1045-1051

62. Tauber M, Gordon K, Koller H, Fox M, Resch H (2009) Semitendinosus tendon graft versus a modified Weaver-Dunn procedure for acromioclavicular joint reconstruction in chronic cases: a prospective comparative study. Am J Sports Med 37:181-190

63. Tauber M, Valler D, Lichtenberg S, Magosch P, Moroder P, Habermeyer P (2016) Arthroscopic stabilization of chronic acromioclavicular joint dislocations: triple- versus single-bundle reconstruction. Am J Sports Med 44:482-489

64. Virtanen KJ, Savolainen V, Tulikoura I, Remes V, Haapamäki V, Pajarinen J, Björkenheim J-M, Paavola M (2014) Surgical treatment of chronic acromioclavicular joint dislocation with autogenous tendon grafts. SpringerPlus 3:420

65. Vitali M, Pedretti A, Naim Rodriguez N, Franceschi A, Fraschini G (2015) Vascular graft employment in the surgical treatment of 
acute and chronic acromio-clavicular dislocation. Eur J Orthop Surg Traumatol 25:1205-1211

66. Wang G, Xie R, Mao T, Xing S (2018) Treatment of AC dislocation by reconstructing $\mathrm{CC}$ and $\mathrm{AC}$ ligaments with allogenic tendons compared with hook plates. J Orthop Surg 13:175

67. Wang Y, Zhang J (2014) Acromioclavicular joint reconstruction by coracoid process transfer augmented with hook plate. Injury 45:949-954

68. Weinstein DM, McCann PD, McIlveen SJ, Flatow EL, Bigliani LU (1995) Surgical treatment of complete acromioclavicular dislocations. Am J Sports Med 23:324-331

69. Wood TA, Rosell PAE, Clasper JC (2009) Preliminary results of the "Surgilig" synthetic ligament in the management of chronic acromioclavicular joint disruption. J R Army Med Corps 155:191-193
70. Wright J, Osarumwense D, Ismail F, Umebuani Y, Orakwe S (2015) Stabilisation for the disrupted acromioclavicular joint using a braided polyester prosthetic ligament. J Orthop Surg (Hong Kong) 23:223-228

71. Xará-Leite F, Andrade R, Moreira PS, Coutinho L, Ayeni OR, Sevivas N, Espregueira-Mendes J (2019) Anatomic and nonanatomic reconstruction improves post-operative outcomes in chronic acromio-clavicular instability: a systematic review. Knee Surg Sports Traumatol Arthrosc 27:3779-3796

Publisher's Note Springer Nature remains neutral with regard to jurisdictional claims in published maps and institutional affiliations.

\section{Affiliations}

\section{Giuseppe Sircana ${ }^{1} \cdot$ Maristella F. Saccomanno $^{1}$ (1) $\cdot$ Fabrizio Mocini $^{1} \cdot$ Vincenzo Campana $^{1} \cdot$ Piermarco Messinese $^{1}$. Andrea Monteleone ${ }^{1} \cdot$ Andrea Salvi $^{2} \cdot$ Alessandra Scaini $^{2} \cdot$ Almerico Megaro $^{3} \cdot$ Giuseppe Milano $^{2,3}$}

Giuseppe Sircana
gsirca@ hotmail.it

Fabrizio Mocini

fabriziomocini90@gmail.com

Vincenzo Campana

dr.vincenzocampana@gmail.com

Piermarco Messinese

piermarcomessinese@ libero.it

Andrea Monteleone

andreamonte8@live.it

Andrea Salvi

ndreasalvi88@yahoo.it

Alessandra Scaini

alescaini@yahoo.it
Almerico Megaro

almericomegaro@hotmail.com

Giuseppe Milano

giuseppe.milano@outlook.it

1 Orthopaedics Institute, Fondazione Policilinico Universitario A. Gemelli IRCCS, Largo A. Gemelli 8, 00168 Rome, Italy

2 Department of Medical and Surgical Specialties, Radiological Sciences, and Public Health, University of Brescia, Brescia, Italy

3 Department of Bone and Joint Surgery, Spedali Civili, Brescia, Italy 